San Jose State University

SJSU ScholarWorks

Faculty Publications

Communication Studies

$1-3-2020$

\title{
Implementing routine communication about costs of cancer treatment: Perspectives of providers, patients, and caregivers
}

\author{
Marie Haverfield \\ San Jose State University, marie.haverfield@sjsu.edu
}

\author{
A. E. Singer \\ University of California, Los Angeles \\ C. Gray \\ VA Palo Alto Health Care System
}

A. Shelley

VA Palo Alto Health Care System

A. Nash

VA Palo Alto Health Care System

See next page for additional authors

Follow this and additional works at: https://scholarworks.sjsu.edu/comm_pub

Part of the Communication Commons, and the Oncology Commons

\section{Recommended Citation \\ Marie Haverfield, A. E. Singer, C. Gray, A. Shelley, A. Nash, and K. A. Lorenz. "Implementing routine communication about costs of cancer treatment: Perspectives of providers, patients, and caregivers" Supportive Care in Cancer (2020): 4255-4262. https://doi.org/10.1007/s00520-019-05274-2}

This Article is brought to you for free and open access by the Communication Studies at SJSU ScholarWorks. It has been accepted for inclusion in Faculty Publications by an authorized administrator of SJSU ScholarWorks. For more information, please contact scholarworks@sjsu.edu. 


\section{Authors}

Marie Haverfield, A. E. Singer, C. Gray, A. Shelley, A. Nash, and K. A. Lorenz 
Running head: COSTS OF CANCER

Implementing Routine Communication About Costs of Cancer Treatment:

Perspectives of Providers, Patients, and Caregivers

Authors: M. C. Haverfield, PhD, ${ }^{1,2,3}$ A. E. Singer, PhD, MD, ${ }^{4}$ C. Gray, $\mathrm{PhD},{ }^{2}$ A.

Shelley, ${ }^{2}$ A. Nash, $M S,{ }^{2}$ K. A. Lorenz, MD, $\mathrm{MS}^{2,3}$

Affiliations: ${ }^{1}$ San José State University Department of Communication Studies, $220 \mathrm{E}$

San Fernando Street, San Jose, CA 95112; ' VA Palo Alto Health Care System Ci2i,

795 Willow Road, Menlo Park, CA 94025 USA; ${ }^{3}$ Stanford University School of Medicine,

1265 Welch Road, Stanford, CA 94035 USA; ${ }^{4}$ UCLA Department of Medicine, 100

Medical Plaza Driveway, Los Angeles, CA 90095 USA

Funding: This work received partial support from the Center for Innovation to Implementation (Ci2i) VAPAHCS, Locally Initiated Project.

Corresponding Author: Marie Haverfield, PhD, 220 E San Fernando Street, San Jose, CA 95112, marie.haverfield@sjsu.edu, ORCID: 0000-0003-2949-0229

Presentations: Study presented at the American Academy of Hospice and Palliative Medicine (AAHPM) Assembly, March 2018.

Disclaimers: There are no disclaimers to report. 


\section{Abstract}

OBJECTIVES Rising costs in oncology care often impact patients and families directly, making communication about costs and financial impacts of treatment crucial. Cost expenditures could offer opportunities for estimation and prediction, affording personalized conversations about financial impact. We sought to explore providers', patients', and caregivers' preferences towards implementing communication about cost, including when, how, and by whom such information might be provided.

METHODS We conducted semi-structured phone interviews with a diverse population including 12 oncology providers, 12 patients, and 8 patient caregivers $(\mathrm{N}=32)$. The constant comparative method was used to identify mutually agreed upon themes. RESULTS Participant groups differed in their concerns surrounding cost communication, namely whether they want to receive this information and how such information might impact provider and patient treatment decisions. All participants agreed that oncology providers should not be leading cost conversations. Patients and caregivers identified social workers or financial advisors as most equipped to communicate about cost. Participants emphasized timely cost conversations, ideally around the time of diagnosis. Participants favored various metrics of financial impact beyond overall costs of care including disability, days lost from work, and out-of-pocket expenses.

CONCLUSION Cost transparency should be incorporated in usual care however, there are several challenges to making cost conversations a part of everyday practice. Patients and family members need resources related to cost to aid in decision making 
and those delivering cost information should have competency in oncology, financial advisement, and patient-centered care.

Keywords: financial toxicity, cost estimates, qualitative research, cancer care, patientprovider communication, implementation 


\section{Introduction}

Out of pocket costs in cancer care are skyrocketing along with a burgeoning number of treatments that test the tolerance of health systems and patient-family affordability.[1-3] In the US, although there are new treatment options for most types of cancer, the cost disparity for this illness has increased dramatically while health insurance coverage has become less reliable, often resulting in patients (and their families) becoming responsible for a greater portion of their care through co-pays and co-insurance.[4] Due to the rise in both out-of-pocket and system-wide costs, organizations including the American Society of Clinical Oncology (ASCO) and the Institute of Medicine emphasize communication between patients and physicians about cancer costs as a standard practice for high-quality care.[5,6] There is hope that communicating about costs might reduce unnecessary expenditures in diagnostic testing and lead to identifying costreducing treatment options.[7] Further, recent research finds that discussing costs with patients is associated with improved patient satisfaction and may influence patient decision-making.[8-10] Despite support for discussing costs, there is no consensus on what constitutes best practices.

In the U.S., precisely estimating individual costs of care is difficult due to differences in coverage, conditions, and health care networks. Uncertainty about costs of care generated by a particular set of treatments may further impair the meaningfulness of introducing the subject of cost in healthcare encounters.[11] Predictive modeling or big data analytics, which is more commonly used for estimating prognosis, is beginning to crossover into evaluating cost outcomes.[12] Cost estimations are currently restricted to major health insurance programs such as 
Medicare. However, it is likely that these cost estimate tools will reach a broader population as the need for this information continues to grow.[13] Furthermore, important aspects of treatment such as charges for specific high-cost drugs or workrelated disability may be feasible, even if overall costs remain elusive to predict.

Therefore, it is critical to identify how to effectively navigate patient-provider conversations about costs and financial impacts of cancer treatment. Many patients and families desire to discuss and understand treatment costs.[14] On the other hand, most providers are underprepared and uncomfortable leading such discussions.[15] Further, the timing of when to discuss costs is not well documented.[16] Ethical issues also arise as patients and providers alike express concerns for how cost and financial information could impact treatment choices.[7] Given the rising financial liability that patients and families face for cancer care, and the growing potential of predictive analytics, we set out to explore providers', patients', and their caregivers' preferences related to discussing cost and other financial impacts of cancer care.

Informed by the Consolidated Framework for Implementation Research, we interviewed participants to characterize important aspects of implementing routine cost communication including when, how, and by whom such information should be communicated.[17]

\section{Methods}

We conducted 32 semi-structured phone interviews with patients $(n=12)$, providers (i.e., chaplain, social workers, nurses, physicians; $n=12$ ), and caregivers $(n=8)$ from Stanford University outpatient oncology clinics. The goal was to recruit a diverse number of providers as well as include the patient and family member voice. Rather than 
comparing disciplinary and patient - family perspectives definitively, we had the goal of exploring the range of perspectives regarding cost communication in cancer care. We focused on implementation, and developed our questions to reflect elements of the Consolidated Framework for Implementation Research.[17,18]

We recruited participants through the oncology department, clinic email announcements, and online listservs. Eligible providers, patients, and caregivers were at least 18 years of age and provided or received care at the Stanford Cancer Centers. The study sample included mostly Females (71\%) of White/Caucasian decent (80\%). Table 1 provides a breakdown of cancer types among patients and caregivers of patients as well as provider specialty. Health conditions among patients ranged from remission from chronic lymphocytic leukemia to persistent low-grade ovarian cancer on hospice. Most patients were insured. The majority of providers were oncology clinicians (73\%) with work ranging in neuro-oncology, hematology, bone marrow transplant, and palliative care (see Table 1). We provided a $\$ 25$ incentive to patient and caregiver participants. The Stanford University Institutional Review Board (IRB) approved this study and all participants completed oral consent before participating.

We conducted and recorded interviews over the phone, and later transcribed them verbatim using a professional transcription service. Following the development and piloting of an interview guide informed by the Consolidated Framework for Implementation Research (CFIR),[17,18] the first and second authors conducted interviews between December 2016 and May 2017. Interview questions were consistent across the three participant groups (see Appendix 1 for Interview Guide). Interviews lasted approximately 45 minutes and addressed diverse topics relevant to 
communication in the cancer encounter. We discussed the general application of prognostic information, patient-family centered outcomes, and communication about costs of care in the cancer encounter. Interviews covered general perceptions (e.g., how information might affect treatment decision-making), how information should be provided (i.e., features of communication), and how cost communication might be implemented in practice.

We analyzed transcripts using the constant comparative method and coded text where participants reflected on aspects related to costs. Following preliminary analyses, the lead author (M.H.) developed a tentative codebook based on thematic saturation. Another research team member (A.S.) applied and refined the codebook and met with the lead author to confirm codes and sub-categories. A third member of the research team (A.N.) separately analyzed the data using the revised codebook. All three team members reconciled their coding across transcripts to confirm key themes. A fourth member of the research team (C.G.) examined quotes representative of each code and helped resolve discrepancies with the lead author. All analyses used Atlas.ti software.

\section{Results}

We identified four main thematic domains related to implementing cost communication across participant groups: benefits of cost information; potential drawbacks to having cost information; who would deliver this information (including conversational characteristics); and the timing for delivering cost information. Table 2 provides practice insights for each domain based on themes reflected across all three groups.

Benefits of Cost Outcome Information 
Participants generally agreed that the possibility of predicting the costs of cancer care was desirable, largely because it would allow patients and families to prepare financially for the impending expense of treatment(s). Among the patient and caregiver participants, having access to future costs of care also afforded them the ability to decide whether or not they should pursue a particular type of treatment.

"I think the out [of] pocket cost is important for people who leave family behind. And being sure that their loved ones that are left behind have adequate finances to continue. It may be that the cost is simply not worth the predicted results of the treatment." (Patient, Chronic Lymphocytic Leukemia)

Providers also thought that cost information could prepare patients and families financially, allowing for a much better patient experience.

"So if they [patients] have a fairly predictable way of looking at that [cost], they [patients] have some financial resources, they [patients] know that they're going to be able to meet this need, it's not going to cost them [patients] their bank account, that's going to make a much better patient experience than the surprise where we just see people drop off the map." (Provider, Chaplain)

\section{Potential Adverse Effects of Cost Outcome Information}

Participants also raised several concerns should costs and financial impact predictions become readily available. Some feared providing such information might negatively impact treatment choices.

"For me, I think I would rather they [provider] not disclose the cost...Because it makes me feel less liability, so I can focus on the treatment. Because actually, 
without knowing the cost, I would choose the best treatment for myself. If I know the cost, then I might have a second doubt." (Patient, Acute Lympho Leukemia) Some participants took issue with how cost information would be used, and in particular, patients were largely concerned about the potential for cost information to influence what treatment options providers offer.

“...I think I would want that [cost estimates], but I wouldn't want it at the expense of bureaucrats or even my provider deciding a priority that something is too expensive and therefore-we're not even going to consider that." (Patient, Brain Cancer)

Conversely, providers worried that patients might misinterpret predicted cost estimates. "My only concern would be that they [patients] interpret it, just like any data, incorrectly. I think some clinicians or people in the healthcare field would say, 'Well, we shouldn't talk about costs at all." (Provider, Palliative Care Physician) Another widely expressed concern among participants from all three interview groups was the impact that cost predictions could have on decision-making. Specifically, participants were concerned that cost predictions may force providers to make a choice between what is good for the health of the patient, and what may be most beneficial on a financial level.

"There are a lot of different ways you can use data to drive different outcomes. And if I'm [the provider] using this to make the hospital look better, if I'm using this to drive down my costs, if I'm using this for purposes other than what's best for the patient and what's best for the family, then there is a danger there." (Family, Husband of Patient) 
"I think part of it would be...my own kind of moral distress around if l'm going through different options and one option's really expensive and knowing or seeing that I felt like it's the right plan, if I say I may not go with that option or choose that option because of financial reasons how would that make me feel from my perspective?" (Provider, Palliative Care Physician)

\section{Delivery of Cost Outcome Information}

Participants highlighted ideal characteristics that the deliverer of cost information should possess, including empathetic communication skills, knowledge of finances and financial planning, and clinical expertise in the management of the cancer as well as potential treatment options.

"[lt should be] somebody that has those qualities that...they're sensitive to the issues that the person is facing. And, and knowledgeable about the organization and...a little bit of knowledge about the disease itself." (Patient, Lung Cancer) Participants identified several reasons why clinicians should not be tasked with sharing cost information with patients and their families. Reasons include lacking familiarity with the financial system, as well as not wanting to divert provider focus away from the health of the patient.

"I honestly think it's better if [communicating cost information] is separate from the treatment team just because I think that it's kind of important for patients to know that when you're looking up [that] you're not really looking at the dollars and that kind of thing, and generally we're not. I mean, right now we don't really get a lot of direct information about it. But I think the patient would reasonably be 
concerned that if we start talking to them about the cost of things as their physician then it kind of compromises our role to just kind [of] advocate for what we think the best treatment is." (Provider, Blood Marrow Transplant Physician) Participants most frequently identified social workers as the healthcare professionals perhaps most equipped to deliver cost outcome information. However, some participants noted that there are currently no suitable professional roles among health care staff to execute this work. Instead, they suggested that this might necessitate an entirely new professional role.

"It's someone that-it's almost like it's a unique thing. I don't see nursing doing it;

l'd have the same worries. You know, the medical assistants are already busy doing stuff for new patients. Like, it would almost be like a separate person." (Provider, Palliative Care Physician)

\section{Timing of Cost Outcome Information}

Due to the sensitivity of receiving a cancer diagnosis, deciding when to deliver information about predicted costs of treatment is particularly important. There was some variability across participant responses around optimal timing, with some participants preferring to wait and others wanting cost information as early in the cancer journey as possible. A common thread among the responses surrounding timing was readiness to receive this information, which many noted was best done after patients and family members had time to absorb and come to terms with the cancer diagnosis and prognosis.

“I would put it in after the tests have been run and after the surgeon's really gotten a good chance to examine me. Take a good look, do a repeat visit if 
necessary but at that, at the point at which l've been seen, it's been diagnosed, everybody's got a really good grip on what it is. I think at that point people should have an option [for cost information]." (Patient, Papillary Thyroid Cancer)

"I don't think it should be at the time, at the delivery of diagnosis. I think that patients and family members might need a little bit of time to let things soak in, but as treatment decisions are made or discussions are talked about what's down the road...that would be useful." (Family, Wife of Patient)

Participants also noted the need to revisit cost estimates as patient health or treatment options progress and possibly change. Waiting for patients to express interest in cost information was likely too late, as the following comment from a provider emphasizes:

"The biggest decisions happen at the time of diagnosis and initiation of therapy. So, that would be the logical time. I guess this is sounding a little bit obvious, but any time before we change therapy, we'd want to reevaluate and see that [cost] information...Waiting until there was an impact or until the patient expressed concern, I think those... are too late. That's currently what we're doing and that's, I think, a disservice to patients and their families." (Provider, Clinical Hematologist)

\section{Discussion}

We evaluated what oncology providers, patients, and family members feel about how cost communication should be implemented in practice. Participants identified important considerations for incorporating information about treatment cost and financial impacts into routine cancer care. Availability of individualized cost estimates would facilitate 
financial preparation, potentially reduce the use of excessive treatments, and likely afford a better patient experience. Concerns were raised about how cost information could adversely affect patient-provider decision-making, the possibility of patients misinterpreting cost data, and the ethical dilemmas that access to cost information could present. Participants elaborated on characteristics a person delivering cost information should possess, and appropriate timelines for discussing costs of care.

Clinicians, patients, and families agreed that cost information could help families prepare, but clinicians and patients both raised concerns about negative impacts on decision making. Preparation for financial jeopardy is indeed important, as clinicians noted that high costs may affect compliance with treatment adversely.[19] Patients pointed to the risk of debt from treatments or "financial toxicity" as an important consideration for quality of life.[20] Participants' concerns echo previous research that highlight the various ways in which cost information may negatively impact and/or complicate treatment decision-making.[11] Alternatively, availability of cost information may not necessarily impact which treatments patients choose.[14] Our findings also suggest that providers may be ill equipped to carry out cost conversations, and in some instances they prefer not to have these discussions. Given participant concerns about system-level cost priorities overriding patient and family level priorities, there is likely still a need for discussions at some point, between the patient (and family) and health care provider to ensure transparency when recommendations are made to the patient regarding treatment choice.

Concerns about negative impacts of introducing cost information in the patientphysician encounter reflect a realistic concern that patients may choose to safeguard 
the financial wellbeing of loved ones over their own health outcomes. In the SUPPORT Study, patients indicated that they would be willing to forgo life-sustaining treatments if continuing to use them jeopardized the financial health of their family.[21] The continued erosion of safety nets (e.g., Affordable Care Act) is placing more in the crosshairs of medical bankruptcy.[22] Given that patients themselves care deeply about these issues and the impact of their choices on loved ones, it seems imperative to offer cost discussions in order to provide patient-family centered cancer care. Further, one could argue that it may be unethical not to assess the financial consequences of cancer treatment with patients.[23] Our participants pointed to the need for a clear point person who can deliver cost information, potentially the social worker, and also suggested specific guidance (e.g., the timing) related to such discussions.

These suggestions that someone other than the physician deliver cost information to patients contrasts with previous research.[11] Physicians face several challenges in the context of delivering cost information that may contribute to their general reticence to engage in cost conversations and elucidate why other healthcare professionals may be more equipped. Among these challenges include a lack of knowledge regarding costs of treatment and coverage options specific to an individual patient and minimal or no training on when and how to deliver cost information.[24-26] Physicians may also struggle to navigate tensions between treatment options and cost that could have potential implications on decision-making.[27,28] Given the ethical concerns and physicians' potential lack of understanding regarding accurate costs of treatment demonstrated in our study and others,[29] designating someone other than the physician may have greater utility. 
A variety of staff other than physicians may be best suited for this task with appropriate training. Social workers, case managers, navigators, and others have the potential to play expanded communication roles and might be considered depending on health care setting, staffing, and goals of a particular cost communication intervention. Often, these professional roles already undergo training to deliver patient and family centered care. In addition, their responsibilities do not intrude on the technical diseasefocused advocacy of the physician in the patient-physician relationship, freeing them from some of the ethical constraints that physicians may face in decision making. Further research is needed to identify the training, information, and preparation that teams need to properly engage patients and family members about costs. Notably, participants signaled the importance of addressing other ways cancer care may impact finances, including disability, inability to work, and out-of-pocket costs. These preferences may be a helpful starting point for addressing patients' and families' cost concerns as it relates to their specific health trajectory.

There were a few subtle differences across the three participant groups. The potential adverse effects of the availability of cost outcome information presented the greatest discrepancy between patients/caregivers and providers. While patients and caregivers expressed concerns about how cost information would influence the providers decision-making in terms of what treatment options they would present to the patient, providers were concerned about patients misunderstanding of cost outcome data. Similarly, Aakhus et al. found that patients worried about profiling based on their ability to pay and providers expressed concerns surrounding personal or institutional conflicts of interest.[30] Again, training a member of the health care team who works 
alongside the physician (but is not the physician) to provide cost information to patients and caregivers as part of the cancer care experience may minimize these concerns. There may also be alternative resources to help support navigating the costs of cancer care such as survivorship plans, which provide patients with information on estimated direct and indirect costs as well as ongoing care.[31] Survivorship plans could become a standardized tool for accompanying cost discussions.

Our study has several limitations including that we evaluated a single Cancer Center with a high prevalence of insured patients. Despite that, our cohort of patients, caregivers, and providers generally emphasized the importance of cost communication. We did not achieve a sufficient sample to compare the responses of providers by discipline; nevertheless, our study represents the range of responses among a diverse set of clinical and patient-family stakeholders with regard to cost communication. Our findings from a predominantly female, White/Caucasian sample may not reflect the experiences among other genders and individuals who identify as other race/ethnicities. Relatedly, differences that we observed preliminarily between groups require additional study of larger samples. Our work was qualitative, so it does not represent the prevalence of these issues, but because we structured our questions using an implementation framework, it provides important insights into the matrix of concerns relevant to successful intervention.[32]

In summary, our work supports the emphasis expressed by ASCO and other societies who have endorsed patient communication around cost impacts as an element of patient-family centered care. It highlights the need for team-based, financially informed, and interpersonally competent approaches to communicating such 
information as well as expresses the need for educating the lay public, not just cancer patients and families, about medical costs and participatory decision making. Our work also points to outcomes to track in terms of assessing both the benefits and unintended consequences of cost communication.

Provider concerns regarding their own moral distress also captures a critical, clinical, and societal issue surrounding cost versus benefit. Though each case must be handled on a one-to-one basis, society can affect change in terms of ensuring comprehensive health care support. More research and discussion in this area is warranted. Collectively, findings underscore the cost impacts encompassing disease, decisional, and patient-family goals as outcomes for research. Interventional research is warranted to further understand practices for integrating cost conversations into usual cancer care. 
Table 1. Participant Cancer Specialty and Type

\begin{tabular}{|c|c|c|c|}
\hline & Providers & Patients & Caregivers \\
\hline 1 & $\begin{array}{l}\text { Chaplain to oncology } \\
\text { outpatient palliative medicine }\end{array}$ & $\begin{array}{l}\text { Blood stem cell transplant } \\
\text { for leukemia }\end{array}$ & $\begin{array}{l}\text { Acute myeloid } \\
\text { leukemia }\end{array}$ \\
\hline 2 & Physician & $\begin{array}{l}\text { ALL leukemia with bone } \\
\text { marrow transplant } \\
\text { (remission) }\end{array}$ & $\begin{array}{l}\text { Hodgkin's } \\
\text { lymphoma }\end{array}$ \\
\hline 3 & $\begin{array}{l}\text { bone marrow transplant } \\
\text { attending }\end{array}$ & $\begin{array}{l}\text { Hodgkin's lymphoma } \\
\text { (remission) }\end{array}$ & $\begin{array}{l}\text { Incurable } \\
\text { lymphoma }\end{array}$ \\
\hline 4 & $\begin{array}{l}\text { Social Worker in bone } \\
\text { marrow transplant }\end{array}$ & $\begin{array}{l}\text { Leukemia bone marrow } \\
\text { transplant (remission) }\end{array}$ & Brain cancer \\
\hline 5 & $\begin{array}{l}\text { Social Worker in the infusion } \\
\text { treatment area }\end{array}$ & $\begin{array}{l}\text { ALL leukemia with bone } \\
\text { marrow transplant and } \\
\text { CAR T-cell therapy }\end{array}$ & Did not disclose \\
\hline 6 & Neuro-oncologist & Brain cancer & Did not disclose \\
\hline 7 & $\begin{array}{l}\text { Palliative care physician in } \\
\text { cancer center }\end{array}$ & Brain cancer & Prostate cancer \\
\hline 8 & Clinical Hematologist & Papillary thyroid cancer & Endometrial cancer \\
\hline 9 & $\begin{array}{l}\text { Nurse Coordinate in bone } \\
\text { marrow transplant area }\end{array}$ & Ovarian cancer (hospice) & \\
\hline 10 & $\begin{array}{l}\text { Palliative care physician in } \\
\text { cancer center }\end{array}$ & Lung cancer & \\
\hline 11 & $\begin{array}{l}\text { Bone marrow transplant } \\
\text { physician }\end{array}$ & Cervical cancer (hospice) & \\
\hline 12 & $\begin{array}{l}\text { Bone marrow transplant } \\
\text { physician }\end{array}$ & $\begin{array}{l}\text { Chronic lymphocytic } \\
\text { leukemia }\end{array}$ & \\
\hline
\end{tabular}


Table 2. Insights for Practice

\begin{tabular}{|c|c|}
\hline Domain & Takeaway \\
\hline Benefits of Cost Outcome Information & $\begin{array}{l}\text { - Ability for patients to prepare } \\
\text { impending treatment } \\
\text { - Decrease excessive treatment } \\
\text { spending } \\
\text { - Better patient experience through } \\
\text { cost transparency }\end{array}$ \\
\hline $\begin{array}{l}\text { Potential Adverse Effects of Cost } \\
\text { Outcome Information }\end{array}$ & $\begin{array}{l}\text { - Concern for influence on provider } \\
\text { treatment choice } \\
\text { - Concern for patient } \\
\text { misinterpretation of cost } \\
\text { information } \\
\text { - Ethical dilemma in access to cost } \\
\text { estimates in terms of treatment } \\
\text { choice and decision making } \\
\end{array}$ \\
\hline Delivery of Cost Outcome Information & $\begin{array}{l}\text { Role of the Social Worker in } \\
\text { assisting with cost information } \\
\text { delivery } \\
\text { - } \quad \text { Compassionate approach to } \\
\text { delivery of cost information } \\
\text { - Individual relaying cost information } \\
\text { must be knowledgeable on health } \\
\text { condition and financial systems }\end{array}$ \\
\hline Timing of Cost Outcome Information & $\begin{array}{l}\text { - } \quad \text { Not at the time of diagnosis } \\
\text { - } \text { parly in the disease, after the } \\
\text { team has had and he and health care } \\
\text { prognosis } \\
\text { - Reevaluation of costs of care when } \\
\text { there are changes to health or } \\
\text { treatment }\end{array}$ \\
\hline
\end{tabular}


Conflict of Interest: There are no conflicts of interest to report. The corresponding author has full control of all primary data and agrees to allow the journal to review the data if requested. 


\section{Appendix 1. Interview Guides}

Provider: As you know out of pocket costs and other indirect expenses to patients or families can be substantial, especially with newer treatments or if one considers the impact of caregiving on a family members job. One of the considerations in improving information to patients, based on planned or anticipated care, or perhaps modeling future care is to think about providing information to patients and families about the costs they will bear.

1. Assuming we can make predictions about costs, what information would you like to see provided to you? (OOP costs? Healthcare system costs?)

a. When would you like to see cost information?

2. Assuming we can make predictions about costs, what are your thoughts on providing OOP cost information to patients? What about healthcare system costs?

a. When do you think that information should be presented to patients?

3. How do you feel about personally delivering this information to patients?

a. If not you, who should be the one to deliver information about costs?

b. How do you think this information should be communicated?

4. In what ways might this change how you approach treatment options?

Patient: Patients and families face very different costs for the treatment they are undergoing and cancer medications are getting increasingly expensive. Using the same information, doctors may be able to tell how much your treatments and future care are likely to cost.

1. How would you feel if we could predict your health care system costs for treatments and future care?

2. How would you feel if we could predict your out of pocket costs for treatments and future care? Or the lost income or expenses your family might face as a whole?

3. Who do you believe should deliver cost information to patients and their family members and at what point should cost information be provided?

4. In what ways might this change how you approach treatment decisions?

Caregiver: Patients and families face very different costs for the treatment they are undergoing, and cancer medications are getting increasingly expensive.

1. How would you feel if we could predict health care system costs for your loved one's treatments and future care?

2. How would you feel if we could predict the out of pocket costs for your loved one's treatments and future care? Or the lost income or expenses your family might face as a whole?

3. Who do you believe should deliver cost information to patients and their family members and at what point should cost information be provided?

4. In what ways might this change how you approach treatment decisions? 


\section{References}

1. Kelley AS, McGarry K, Gorges R, et al: The burden of health care costs in the last 5 years of life. Ann Intern Med 163:729-736, 2015

2. Mariotto AB, Yabroff KR, Shao, $Y$, et al: Projections of the cost of cancer care in the United States: 2010-2020. J Natl Cancer Inst 103: 117-28, 2011

3. Ramsey S, Blough D, Kirchhoff A, et al: Washington State cancer patients found to be at greater risk for bankruptcy than people without a cancer diagnosis. Health Aff $32: 1143-1152,2013$

4. Finkelstein EA, Tangka FK, Trogdon JG, et al: The personal financial burden of cancer for the working-aged population. Am J Manag Care 15:801-806 2009 5. Meropol NJ, Schrag D, Smith TJ, et al: American Society of Clinical Oncology guidance statement: The cost of cancer care. J Clin Oncol 27:3868-3874, 2009 6. Ganz PA, Levit LA. Charting a new course for the delivery of high-quality cancer care. J Clin Oncol 31(36):4485-4487, 2013

7. Hunter WG, Zafar Y, Hesson A, et al: Discussing health care expenses in the oncology clinic: Analysis of cost conversations in outpatient encounters. J Oncol Prac 13:e994-956, 2017

8. Shih YT, Chien CR: A review of cost communication in oncology: Patient attitude, provider acceptance, and outcome assessment. Cancer 123(6):928-939, 2017 9. Carrera PM, Kantarjian HM, Blinder VS: The financial burden and distress of patients with cancer: Understanding and stepping-up action on the financial toxicity of cancer treatment. CA: a cancer journal for clinicians 68(2):153-165, 2018 
10. Casilla-Lennon MM, Choi SK, Deal AM, et al: Financial toxicity among patients with bladder cancer: Reasons for delay in care and effect on quality of life. The Journal of Urology 199(5):1166-1173, 2018

11. Riggs KR, Ubel PA: Overcoming barriers to discussing out-of-pocket costs with patients. JAMA 174:849-850, 2014

12. Greiner MA, Hammill BG, Fonarow GC, et al: Predicting costs among Medicare beneficiaries with heart failure. American Journal of Cardiology 109(5):705-711, 2012 13. Hamlet KS, Hobgood A, Hamar GB, Dobbs AC, Rula EY, Pope JE. Impact of predictive model-directed end-of-life counseling for Medicare beneficiaries. Am J Manag Care 16(5): 379-384, 2010

14. Bullock AJ, Hofstatter EW, Yushak ML, et al: Understanding patients' attitudes toward communication about the cost of cancer care. J Oncol Prac 8:e50-58, 2012 15. Schrag D, Hanger M: Medical oncologists' views on communicating with patients about chemotherapy costs: A pilot survey. J Clin Oncol 25:233-237, 2007 16. Damschroder LJ, Aron DC, Keith RE, et al: Fostering implementation of health services research findings into practice: A consolidated framework for advancing implementation science. Implementation Science 4(1):50, 2009

17. Breimaier HE, Heckemann B, Halfens RJG, et al: The Consolidated Framework for Implementation Research (CFIR): A useful theoretical framework for guiding and evaluating a guideline implementation process in a hospital-based nursing practice. BMC Nurs 14:43, 2015

18. Khera N, Holland JC, Griffin JM. Setting the stage for universal financial distress screening in routine cancer care. Cancer 123(1):4092-6, 2017 
19. Brick DJ, Scherr KA, Ubel PA: The impact of cost conversations on the patientphysician relationship. Health Communication 34(1):65-73, 2019

20. Zafar SY, Abernethy AP. Financial Toxicity, Part 1: A new name for a growing problem. Oncology 27:4, 2013.

21. Covinsky KE, Landefeld CS, Teno J, et al: Is economic hardship on the families of the seriously ill associated with patient and surrogate care preferences? SUPPORT investigators. Arch Intern Med 156(15):1737-1741, 1996

22. Himmelstein DU, Lawless RM, Thorne D, et al: Medical bankruptcy: Still common despite the Affordable Care Act. Am J Public Health 109(3):431-433, 2019

23. Zafar YS. Financial toxicity of cancer care: It's time to intervene. Journal of the National Cancer Institute 108(5):djv370, 2016

24. Ubel PA, Abernethy AP, S Yousuf Zafar MD MH. Full disclosure--out-of-pocket costs as side effects. The New England journal of medicine. 2013 Oct 17;369(16):1484.

25. Alexander GC, Casalino LP, Meltzer DO. Patient-physician communication about outof-pocket costs. JAMA 2003;290:953-8.

26. Jagsi R, Ward KC, Abrahamse PH, Wallner LP, Kurian AW, Hamilton AS, Katz SJ, Hawley ST. Unmet need for clinician engagement regarding financial toxicity after diagnosis of breast cancer. Cancer. 2018 Sep 15;124(18):3668-76.

27. Weinstein MC. Should physicians be gatekeepers of medical resources? J Med Ethics. 2001;27:268-274.

28. Emanuel EJ, Dubler NN. Preserving the physician-patient relationship in the era of managed care. JAMA. 1995;273:323-329. 
29. Resnicow K, Patel MR, Mcleod MC, Katz SJ, Jagsi R. Physician attitudes about cost consciousness for breast cancer treatment: differences by cancer sub-specialty. Breast cancer research and treatment. 2019 Jan 15;173(1):31-6.

30. Aakhus E, Rosenstein A, Joffe S, et al: Implementing cost transparency in oncology: A qualitative study of barriers, facilitators, and patient preferences. J of Clin Oncol 35:6597, 2017

31. Coughlin SS, Dean LT. Cancer survivorship care plans, financial toxicity, and financial planning alleviating financial distress among cancer survivors. Supportive Care in Cancer 26(6):1969-71 2019

32. Gueguen JA, Bylund CL, Brown RF, et al: Conducting family meetings in palliative care: themes, techniques, and preliminary evaluation of a communication skills module. Palliative \& Supportive Care 7:171-179, 2009 